\title{
Repurposing Zotero for sustainable assessment and scalable modified embedding
}

Rebecca Kuglitsch

\section{Introduction}

Instruction librarians are pressed for time, often unable to assess student work as deeply as they wish or find time to explore and apply developing practices, such as embedded librarianship. The many competing demands on librarians' time require creativity in approaching new tasks. Repurposing known tools and integrating new practices into existing structures as much as possible can make new approaches more feasible. For assessment and embedding, reimagining and repurposing Zotero, a wellknown citation manager, can provide new avenues to implement assessment and develop embedded librarianship integrated within a tool that librarians may already utilize as a part of their information literacy instruction practices.

Zotero's group libraries feature can be used as platform for embedded librarianship and can also provide a flexible, multi-purpose tool for assessing student research practices. Several characteristics of Zotero $^{1}$ make it a particularly appealing and practical tool for this application. This paper presents a model for how Zotero can be used to assess what students learn and apply from instruction sessions and sustainably develop an on the fly embedding model that extends the opportunity for information literacy assessment beyond the traditional one shot. It will review current challenges for assessment and embedded librarianship, explore how Zotero can address these challenges, and present Zotero's unique tools for assessment in the context of a case study implementation. By using the features of Zotero's group libraries, a librarian can provide modified embedded librarianship services and unobtrusively

\footnotetext{
${ }^{1}$ Zotero is an open source software program created by the Center for History and New Media at George Mason University and is available for download at https://www.zotero.org. This paper is based on version 4.0, which is available as a simple plugin for Firefox, and a standalone application with connectors to Firefox, Chrome, and Safari. Thus, it is supported by browsers that have the majority of the current market share (w3schools, n.d.). Moreover, it is quite user-friendly, and has a well-established open-source model. For students who work on their own laptops, it is easy to install and sync. For those who rely on campus machines, Zotero can be installed to function with roaming profiles, or failing that, can be run from a flash drive.
} 
assess student work. This paper will also consider student reception of the method. Do students find a librarian participating in their research through the citation management tool they're using acceptable and appealing? No matter how useful librarians find Zotero for embedding and assessment, it is useless if students find librarians working with them in Zotero to be intrusive or constraining. However, this case study suggests that students welcome librarian and instructor participation via Zotero and that the tool provides unique opportunities for librarians to expand their services and assessment practices.

\section{Current challenges for embedded librarianship}

While librarians being embedded in face-to-face courses has been very successful in terms of outcomes, it can be a challenge to scale beyond a single course (Schulte, 2012). For example, Hearn's case study of an effective in-person embedding scenario relied on eight class sessions and numerous meetings with students, and suggested that a reduction in regularly scheduled activities would be necessary for librarians to implement similar practices (2005). Though effective, this is simply not a sustainable option for many libraries. Consequently, electronic embedded librarianship has been explored as a more viable option. Electronic embedding can still be difficult to manage sustainably, but offers opportunities to streamline librarian workload and minimize some time challenges (Hoffman, 2011).

However, while online embedding can solve some time problems, it raises new challenges. Managing to access online course space is one of them. Many electronic attempts at embedding have used course management systems (CMS), and their accessibility depends on a wide variety of factors, largely outside the control of a librarian. Most fundamentally, librarians may not have access to the campus CMS. Some information technology (IT) departments cannot or will not support adding librarians into the user groups with access to a CMS. Even on those campuses where librarians can be added to the CMS, some faculty simply choose not to use the systems. When reluctant faculty do choose to use a CMS or are forced to by the university's policies, the CMS may function primarily as an 
online syllabus and site for turning in assignments rather than a space that facilitates discussions about research.

Among those faculty who wholly embrace the CMS to its full potential, some may not be comfortable adding a librarian to their course site. Faculty continue to struggle with what role librarians can play in the classroom, and certainly there is often a protectiveness of classroom space and time (Owusu-Ansah, 2004). While the role of a librarian as a guest lecturer for a session or two is relatively well established, full participation as a co-instructor is less established. If a CMS is positioned as an extension of the classroom it can be uncomfortable for faculty to add librarians to their course sites in roles that make meaningful interactions with students possible. In short, numerous technological, institutional, and social barriers can make it difficult for librarians to fully embed in a CMS.

\section{Zotero as an embedding solution}

Using Zotero addresses some of the challenges posed by online embedded librarianship via CMS. As a lightweight, easily installed tool, it does not call for assistance from often overstrained IT or educational technology departments. As a tool whose use can transcend the classroom, Zotero sidesteps issues of classroom authority. While the success of Zotero as a tool for embedded librarianship relies on support from the instructor and a need in the classroom, it ultimately is an individual citation management tool, rather than a tool developed to extend the classroom, like a CMS. Thus, the librarian presence in Zotero can evade challenging questions that long-term classroom or CMS presence can raise.

Additionally, it is quite simple to set up a group in Zotero. A group allows users to share citations, subcollections and notes in a particular collection in their group libraries. In this case study, the group collection was shared between a librarian, an instructor and students. Once a group is set up, the librarian can communicate with students, adding potential sources and leaving notes on existing sources in the collections that belong to that group. The groups can be shared so that only the librarian and 
instructor have access to each collection, or a group can be set up with a main collection that has subcollections for each student project that everyone can access and collaborate in. These very practical reasons make Zotero a good candidate for a solution to the CMS embedding problem.

Not only is Zotero a practical solution, using it also aligns with librarians' instructional goals. Citation management tools are usefully introduced when researchers are participating in long-term collaborative projects that use a significant number of citations (Childress, 2011). By using Zotero, the librarian can situate communication about research resources within a tool of actual long-term research utility to students. Students benefit more from leaving college with the skills to use an open source information management tool rather than honing skills useful only within an institutionally-bounded CMS. Even more than simply teaching useful mechanical skills, using Zotero as a means of communication introduces the idea of managing information in a collaborative context rather than simply searching and finding. This is one of the knowledge practices relating to searching as exploration, one of the frames for information literacy that the Association of College and Research Libraries (ACRL) has developed (ACRL Information Literacy Competency Standards for Higher Education Task Force, 2014). Not only does using Zotero for embedding provide librarians with an opportunity to teach students a practical skill, it frames that skill within the context of the larger concept of searching as exploration, an idea students must master to become information literate.

\section{Zotero for assessment}

Zotero is useful for assessment as well as embedded librarianship. Indeed, the aspects of embedded librarianship which it supports extend the opportunities for assessment, particularly formative assessment throughout the course. A librarian added as a collaborator in students' group libraries can observe student work, identify areas of difficulty quickly, and provide follow-up information addressing confusion throughout the students' project. Additionally, Zotero also allows for a summative assessment 
at the end of a semester or project. The librarian can observe student work and assess the final, overall picture of the student's research. This continued observation greatly extends the timeframe available to librarians for assessment. It is a challenge to truly assess instructional effectiveness when the only contact with a class is a single occurrence; using Zotero it is possible to unobtrusively continue communicating and observing student work over the course of an entire project.

Zotero gives librarians the opportunity to directly evaluate student performance, and capitalizes on one of the advantages of observing performance-the fact that students are simply required to produce artifacts like bibliographies, papers, or in this case, Zotero collections as a part of the class experience (Schilling and Applegate, 2012). This is an advantage over assessment that requires students to generate a separate piece of work. However, as observation by Zotero is a measure of performance rather than attitude, it cannot be used to gauge affective aspects of information literacy such as an inclination to use the tool independently, or motivation to manage research with it in the future (Schilling and Applegate, 2012). This measure of performance can easily be supplemented with surveys that would assess this affective aspect of information literacy, as they were in this case study. Indeed, since Zotero can make the librarian's participation more long-lasting than a single instruction session, it may be easier to assess affective aspects of learning via survey or questionnaire, since students will retain a connection to the library longer and may therefore be slightly more likely to respond.

\section{Assessment tools}

Zotero's capacity for assessment ranges from the very simple to the exceedingly sophisticated. By using the group libraries feature, it is possible for a librarian added as a member of the group to see a snapshot of research at a particular time. It is also possible to sort, order, and assess sources in shared collections. Another feature native to Zotero is the timeline tool, built on MIT's SIMILE widget platform, which allows a user to see sources mapped over time-by publication date, date added to library, or 
modification date. For more sophisticated analysis, it is possible to export Zotero libraries to Microsoft Excel or another spreadsheet program, or to use an addon called Paper Machines, originally designed for the digital humanities but allowing for quick visualizations of topics, geographic regions and more. All of these tools can be mapped to observable actions that demonstrate the knowledge practices relating to the draft ACRL Information Literacy Framework (ACRL Information Literacy Competency Standards for Higher Education Task Force, 2014).

[Insert Table One]

\section{Browsing shared collections}

Simply browsing shared collections can tell the librarian a surprising amount about student success, and is particularly useful for impressionistic formative assessment. First, of course, the librarian can quickly see whether students are using Zotero at all. They can see what kind of resources the students are using, or not using, and what publications are being used. The librarian can also get a quick, holistic sense of how students are using library tools over time. While unsophisticated, these quick glimpses are very useful when a librarian may have an opportunity to communicate with students individually or as a group and correct misapprehensions or suggest further avenues for research.

\section{Sorting \& ordering collections}

For more detailed analysis, using the sort and order feature in Zotero makes it possible to see what database or source was used to add materials to the collection. Zotero users can choose what fields are displayed in the collection view, allowing librarians to quickly and easily adjust the display to show the fields that are meaningful for their assessment. Then, the displayed fields can be used to sort and group citations. For example, the library catalog field can group citations by where they originated, making it 
possible to see if students are adding books from the library catalog or Amazon, articles from specialized databases or other locations. A librarian might wish to see publications added from PubMed or Web of Science in a biology course, for example. On the other hand, if instruction has focused on finding and accessing full text, a librarian might look for additions of articles directly from journal sites.

It is also possible to quickly sort by publication date, which can be an avenue to assess whether students understand the scholarly conversation. Do the times of publication, for example, match the standards of the field? Are science students using more recent contributions, and history students both recent and older publications? The librarian can determine whether students demonstrate a sense of a scholarly conversation over time, tying in to the information literacy frame of scholarship as a conversation (ACRL Information Literacy Competency Standards for Higher Education Task Force, 2014). This offers significant opportunities for assessment, and would be particularly powerful if the librarian also has access to the students' final papers.

\section{Timeline}

Zotero's timeline feature is a versatile option for visualizing several aspects of student research. It allows the assessing librarian to quickly visualize a collection or subcollection temporally. Items in the selected collection are mapped onto a modifiable timeline. This is particularly useful for visualizing when items have been added to a particular collection or subcollection.

Because Zotero uses different icons for different types of sources, it is also very easy to quickly track how a student or group's research process has progressed. This could, for example, be used to assess student's grasp of the iterative nature of research - in this case, seeing students adding resources over time, rather than all at once, would suggest that they were beginning to understand research as a process that raises new questions and avenues of inquiry. This ties in to the information literacy frame of research as inquiry (ACRL Information Literacy Competency Standards for Higher Education Task 
Force, 2014). Another example, in this case format as process, could include looking for evidence of students beginning their research with broad background sources, and then progressing to more specific sources appropriate to their disciplinary norms (e.g. peer reviewed articles for biology, or monographs for history) (ACRL Information Literacy Competency Standards for Higher Education Task Force, 2014). Using Zotero, a librarian could check very rapidly and on the fly to see if students are beginning with reference or general book sources and then moving to articles or other narrower, focused source types. This quick assessment could inspire adjustments in subsequent instruction sessions or follow ups via research consultations.

To use the timeline, the librarian need simply select the collection or subcollection of interest, then click on the actions (gear) menu in Zotero, and select 'Create Timeline.' Then, it's possible to select the relevant dates to map and whether to filter the mapped points using free text. The default timeline settings provide three bands: month, year, and decade. These can be adjusted upwards and downwards, from day to millennium. For librarians trying to visualize students' research process, this is a quick, effective way to take a holistic look at the process.

\section{Spreadsheet Analysis}

For most source type assessments, it is easy to quickly assess student work solely using the sort and filter function discussed above. However, more fine-grained analyses can be performed using a spreadsheet program. For example, in this project, the author was interested in whether students were using journals that matched their topic areas. One could sort, filter, and count journals. But it is much easier to export the bibliographic resources to a spreadsheet program and use pivot tables to generate graphs of the most used journals. For example, the author could quickly see that the students focusing on climate change used primarily journals from the scientific literature, and in particular journals that 
are strong in climate change research, matching an outcome for the instruction session: using appropriate sources for each topic.

As of September 2014, Zotero has the capacity to directly export records to a characterseparated value file (.csv), a format for tabular data that can easily be opened by a spreadsheet program such as Microsoft Excel. This is substantial improvement in the user experience for spreadsheet analysis, as it provides an unintermediated experience for the user and a more comprehensive set of data for analysis. Prior to this change, spreadsheet analysis required exporting a subcollection as a BibTeX file, opening it in JabRef (a graphic user interface for BibTeX software), and saving as a .csv file, then analyzing the data. That method only allowed analysis of the fields exported to BibTeX, limiting what could be explored. Zotero's direct export to .csv exports all fields of the records added, making it a much more powerful analysis tool.

\section{Paper Machines}

Paper Machines was initially developed as a tool for enhancing access to computational analysis in the digital humanities (Crymble, 2012). Consequently, it is one of the more sophisticated tools available for analysis, and is quite different than the preceding tools in that it analyzes the text of attached documents rather than just the metadata of the resources students are using. For analysis, these texts must be either plain text or PDFs with optical character recognition. It is highly useful for assessing spatial aspects of sources students are using, and can provide a much more sensitive analysis of the types and content of sources students use than simply assessing the metadata. Paper Machines's textual capacities include a word cloud feature that can be adjusted to produce several types of clouds, a phrase net tool, a topic modeling tool, and several mapping tools ("How to Use Paper Machines", n.d.). It can generate flight paths linking place of publication to places mentioned in the text as well as heatmaps of places mentioned in the texts. Thus, it is helpful for assessing relevance and, perhaps, 
schools of thought students are applying to a problem and whether they are exploring international literature as appropriate. However, the tool's sophistication is both a strength and a limitation. Using it requires that the librarian be able to identify the vocabulary and locations that matter-an easy task in the case of relevance, but perhaps less easy if assessing schools of thought or theoretical approaches. Moreover, in fields where it is unlikely that full text will be available in Zotero, Paper Machines is necessarily limited. Still, for librarians with a clear understanding of the tools it provides, and familiarity with student topics, Paper Machines can make complex analysis exceptionally rapid.

\section{Setting up Zotero in the class}

The author was able to explore the use of Zotero as an assessment and embedding tool over the course of a semester in a small Environmental Justice course (seven students) populated mainly by juniors and seniors with liberal arts majors. Their culminating project asked each student to write on one aspect of an overarching environmental justice problem. This assignment, in which each student approached the same topic from a different perspective, naturally fostered a collaborative environment and was a good fit for working with a citation management tool as it required students to engage with a significant number of resources (an average of fourteen (14) sources were added to each project folder by the end of the semester, with one student peaking at twenty-seven (27) resources).

Working with the instructor, the author arranged an initial library session early in the semester. Prior to this session, students were expected to install Zotero on their own laptops and learn how to use the software. This was intended to leave plenty of time to learn to use Zotero's group libraries feature during the instruction session as well as information literacy concepts. Students were provided with step-by-step handouts and short videos demonstrating how to install and add materials to Zotero. All arrived for the first session with Zotero installed, most were able to use the tool on their own, and those few who could not had clear questions about the obstacles they had encountered. After an introduction 
that addressed any lingering confusion, the author explained Zotero group libraries for the class during the session and set up a class group with subcollections for each student. It was decided to set up the group during the session because, while basically straightforward, it is a somewhat more complicated process than setting up individual libraries. Moreover, learning to set up a group in Zotero was a skill the author wanted to model for the students as it is more transferable than a one-time software installation.

\section{Setting up Zotero for assessment and embedding}

Zotero libraries, including group libraries, allow setting up collections with subcollections. In group libraries, permissions for access to subcollections flow downwards from the main collection. For this class, then, the author set up one overarching group collection, which each student, the instructor, and the librarian could access. Then, within the overarching folder, each student project had a subfolder. Everyone could add to an individual's subcollection, but it was agreed that each subcollection was a particular student's domain. During the class, the author added materials to the larger group collection, and, as appropriate, to individual student subcollections.

After setting up the group collection, the author moved into an information literacy session, with a number of desired outcomes:

- Students will use Zotero in order to manage their research resources efficiently;

- Students will use a wide range of appropriate source types in order to answer complex questions that require more than a few scholarly articles;

- Students will use library resources and strategies taught in the instruction session in order to efficiently obtain the resources they discovered; and

- Students will understand that research is an iterative process in order to fully engage with challenging questions. 
[Table Two]

Each of these outcomes was mapped to a set of observable actions. Then, the observable action was paired with the Zotero tools that can facilitate assessment, as seen in Table 2 . Some are extremely simple-for example, assessing whether students used Zotero was as straightforward as checking whether student groups had actually added material to their folder. Others, such as assessing whether students used a wide range of sources, could be assessed in a variety of ways using nearly any of the tools; selecting one was a question of deciding whether speed or detail were more important.

\section{Changes made in instruction}

Using these tools, it was possible to identify some changes that would immediately enhance instruction efficacy. Students most consistently showed difficulty with the frame of research as inquiry, for example. A few groups added resources over a period of time, but most added resources all at once, just before the due date and just after the second instruction session. In future sessions, the author hopes to address this by scaffolding deadlines and requiring students to add some resources to the group collection before the second session. Shifting the second instruction session to be a few weeks before the deadline, rather than a few days, and discussing the resources added during the second session are simple structural changes that will support student understanding of research as process of inquiry, rather than a discrete activity.

Students also had difficulty exploring resources not found in typical library databases. Most of the resources they used were articles, books, or book chapters. Introducing searching techniques for these less typical sources earlier would be productive. In order to fully explore their topic-a recent event and how it affected local populations-students needed to use grey literature, local government 
and Federal Emergency Management Agency reports, blogs, and social media sources. Focusing on library resources during the first session left students with gaps in their sources and search skills. However, the variety of grey literature and the span of student inquiry made it difficult to address these gaps in a single library session. In the next iteration of the course, the author has arranged office hours for individual research sessions to address these necessarily more focused needs.

Additionally, survey feedback showed that students had a relatively shallow understanding of privacy in Zotero. Some, for example, expressed privacy concerns about other users seeing their private libraries, rather than the shared group collections, a scenario that is not possible with Zotero. While student understanding of privacy as an issue is commendable, they needed more information on the mechanics of Zotero's collaboration features to grasp its full potential. Moreover, further discussion of the privacy features can bring up questions about privacy and the cloud for those students who might not otherwise be aware of the issues. Thus, in future sessions, the author will provide more information about the mechanics of the collaboration features of Zotero and plans to explore issues of online privacy more thoroughly.

\section{Student Responses}

Overall, the students were positive about the presence of a librarian in their citation manager. Out of a class of seven, the author received six survey responses addressing questions about student perceptions of the use of Zotero as a tool and of working with a librarian and their instructor using it. All but one student agreed or strongly agreed that they would be comfortable with a librarian making comments on articles in their Zotero group libraries. Similarly, all but one agreed that they would be comfortable with a librarian or instructor adding items to their collection in the group libraries, with more students strongly agreeing that they would like their instructor to add to their collection in the group libraries. One student strongly disagreed with the statement that they would be comfortable with a librarian or 
instructor adding or commenting on their shared collections. However, each surveyed student provided free text comments, and no free text comments reflected this strong disagreement, so there may have been some confusion about the survey. Two comments did reflect some ambivalence, but the concerns were easily addressed. For example, one student wanted private folders, which Zotero provides, and one student simply reiterated that they wished to control access to their folders to people they knew. These comments, in fact, were an unexpected but positive demonstrations of students seeking to manage their online presences responsibly, one of the knowledge practices tied to the frame "Information has Value" (ACRL Information Literacy Competency Standards for Higher Education Task Force, 2014).

Ultimately, several themes emerged from the students' free text responses. Students appreciated assistance, particularly assistance from a known, authoritative source; they appreciated the opportunity to communicate about research efficiently; and they expressed concerns about privacy and control of access.

\section{Appreciation for assistance}

- $\quad$ "Having more people adding sources is like having devoted more time to research myself without needing to actually spend the time."

- "It is helpful to look at what other students have to say. And having librarian/instructor access would be super helpful rather than having to deal with emails, etc."

- "Comments would inform me as to which items were actually relevant and worth investigating further."

- "Any help I could get is awesome, as long as they labeled that it was their comments and not mine" 


\section{Efficient communication}

- "Easy way to transfer information effectively"

- "Easier to manage information in one place."

- "It's a great way to share information, especially on group projects. It would just be helpful if there was a way to mark it as unread if someone else was adding it."

- "It would be really useful to work directly through Zotero rather than through email :)"

- "Effective way of giving feedback, although google docs was more helpful in combining information"

\section{Concerns about privacy}

- "I might want a folder that only I have access to, but group folders are useful for sharing info"

- "It might depend on whether I have met the people who are commenting. So far I have used Zotero for my own project and a small group project with 7 students, 1 professor and 1 librarian, all of whom know each other."

Regardless of their opinions about librarian participation in their Zotero group libraries, all of the students indicated that they were likely or very likely to use Zotero in the future. All but one had already applied Zotero for their other courses, and the non-user noted that they could not apply it, as no other course that term required research. Students clearly appreciated learning a transferable tool that improved their research and citation experience. Thus, students were both positive about Zotero and having a librarian participate in their research using Zotero.

\section{Conclusion}


Overall, Zotero provides unique, low-investment options for assessment, both formative and summative, as well as opportunities for a modified version of embedded librarianship that can extend the timeframe available for assessment. Zotero's tools are designed to let a researcher assess their own collection quickly - but librarians can turn these tools to good use and assess the work of students effectively. In general, students are open to this observational approach. Indeed, when observation via Zotero is used as a formative assessment and students have been informed that someone they know will be participating in their Zotero group libraries, students appreciate having librarian and faculty input. Moreover, it is clear that students appreciated learning to use the tool, and planned to employ it in future research projects. Thus, Zotero for embedding and assessment provides a solution that addresses librarians' needs for assessment and extends librarian contact with students after initial instruction sessions, while also providing students with a research skill that will serve them well as they complete future research projects. By repurposing a well-known tool, librarians can add new facets to their instruction without overwhelming investments of time and energy. Zotero not only sustains students' research skills but also makes librarians' assessment of instruction more sustainable.

\section{References}

ACRL Information Literacy Competency Standards for Higher Education Task Force. (2014,June17), "Framework for Information Literacy for Higher Education, Draft 2", available at: http://acrl.ala.org/ilstandards/wp-content/uploads/2014/02/Framework-for-IL-for-HE-Draft2.pdf (accessed 29 June 2014).

Childress, D. (2011), "Citation Tools in Academic Libraries: Best Practices for Reference and Instruction", Reference \& User Services Quarterly, Vol. 51 No. 2, pp. 143-152.

Crymble, A. (2012), "Review of Paper Machines, produced by Chris Johnson-Roberson and Jo Guldi", Journal of Digital Humanities, Vol. 2 No. 1. 
Hearn, M.R. (2005), "Embedding a librarian in the classroom: an intensive information literacy model", Reference Services Review, Vol. 33 No. 2, pp. 219-227.

Hoffman, S. (2011), “Embedded academic librarian experiences in online courses: Roles, faculty collaboration, and opinion", Library Management, Vol. 32 No. 6/7, pp. 444-456.

"How to Use Paper Machines". (n.d.). Paper Machines, available at: http://papermachines.org/?page_id=30 (accessed 20 September 2014).

Owusu-Ansah, E.K. (2004), "Information Literacy and Higher Education: Placing the Academic Library in the Center of a Comprehensive Solution", The Journal of Academic Librarianship, Vol. 30 No. 1, pp. 3-16.

Schilling, K. and Applegate, R. (2012), "Best methods for evaluating educational impact: a comparison of the efficacy of commonly used measures of library instruction", Journal of the Medical Library Association: JMLA, Vol. 100 No. 4, pp. 258-269.

Schulte, S.J. (2012), “Embedded Academic Librarianship: A Review of the Literature", Evidence Based Library and Information Practice, Vol. 7 No. 4, pp. 122-138.

w3schools. (n.d.). "Browser Statistics", available at: http://www.w3schools.com/browsers/browsers_stats.asp (accessed 5 August 2014). 


\begin{tabular}{|c|c|c|}
\hline Tool & Observable activity & Information Literacy Frames \\
\hline $\begin{array}{l}\text { Browsing } \\
\text { group } \\
\text { collections }\end{array}$ & $\begin{array}{l}\text { - } \quad \text { Are students using Zotero at all? } \\
\text { - } \quad \text { Are students able to identify and modify } \\
\text { necessary citation components? } \\
\text { - } \quad \text { Quick impressions of sources used }\end{array}$ & $\begin{array}{l}\text { - Research as Inquiry: students will communicate with } \\
\text { collaborators } \\
\text { - Searching as Exploration: move from searching to managing } \\
\text { information } \\
\text { - Format as Process: identify effective formats, understand format } \\
\text { and access are separate, match formats to information needs }\end{array}$ \\
\hline Sort \& order & $\begin{array}{l}\text { - Where are students finding sources? } \\
\circ \text { Sort by library catalogue } \\
\circ \text { Sort by publication title } \\
\text { - Are students using appropriately current or } \\
\text { historical sources? } \\
\circ \text { Sort by publication date }\end{array}$ & $\begin{array}{l}\text { - Format as Process: identify effective formats, understand format } \\
\text { and access are separate, match formats to information needs } \\
\text { - Searching as Exploration: match information needs and } \\
\text { searching to appropriate tools } \\
\text { - Research as Inquiry: use sources that indicate a sense of } \\
\text { scholarly inquiry over time }\end{array}$ \\
\hline Timeline & $\begin{array}{l}\text { - Do students show behaviors that correlate } \\
\text { with research as an iterative process? } \\
\circ \text { Do they add sources over time? } \\
\circ \text { Do source types change over time? }\end{array}$ & $\begin{array}{l}\text { - Research as Inquiry: indicate understanding of research and } \\
\text { learning as processes } \\
\text { - Format as Process: identify effective formats, understand format } \\
\text { and access are separate, match formats to information needs }\end{array}$ \\
\hline $\begin{array}{l}\text { Paper } \\
\text { Machines }\end{array}$ & $\begin{array}{l}\text { - Quick glimpses of content for relevancy } \\
\circ \quad \text { Full-text-derived word clouds } \\
\circ \text { DBpedia graphics } \\
\text { - Geographic pictures of student research-are } \\
\text { students using sources with an appropriately } \\
\text { local or international focus or origin? } \\
\circ \text { Heat maps of geographic locations } \\
\text { mentioned in full text } \\
\circ \quad \text { Flight paths that map place of } \\
\text { publication to places mentioned in the } \\
\text { text }\end{array}$ & $\begin{array}{l}\text { - Format as Process: identify effective formats, understand format } \\
\text { and access are separate, match formats to information needs }\end{array}$ \\
\hline
\end{tabular}

Table One. Zotero tools for assessment mapped to observable activities and the ACRL draft Framework for Information Literacy 


\begin{tabular}{|c|c|c|}
\hline Outcome \& Frames & Observable Actions & Zotero Tool for Assessment \\
\hline $\begin{array}{l}\text { Students will use Zotero in order to } \\
\text { manage their research resources } \\
\text { efficiently } \\
\text { (Research as Inquiry, Searching as } \\
\text { Exploration) }\end{array}$ & $\begin{array}{l}\text { - Save and share material to the group library } \\
\text { - Use Zotero to create citations } \\
\text { - Use Zotero for other research }\end{array}$ & $\begin{array}{l}\text { - Browsing group } \\
\text { collections }\end{array}$ \\
\hline $\begin{array}{l}\text { Students will use a wide range of } \\
\text { appropriate source types in order to } \\
\text { answer complex questions that require } \\
\text { more than a few scholarly articles } \\
\text { (Format as Process) }\end{array}$ & $\begin{array}{l}\text { - Add a variety of source types to the group library } \\
\text { - Use source types that match the research question } \\
\text { (e.g. the group that investigates scientific aspects } \\
\text { uses more scientific publications than the group that } \\
\text { investigates public reaction, which uses informal } \\
\text { media like blogs, interviews, and newspaper articles) }\end{array}$ & $\begin{array}{l}\text { - } \text { Browsing group } \\
\text { collections } \\
\text { - Sort and order } \\
\text { - Timeline } \\
\text { - Export to Excel } \\
\text { - } \quad \text { Paper Machines }\end{array}$ \\
\hline $\begin{array}{l}\text { Students will use library resources and } \\
\text { strategies taught in the instruction } \\
\text { session in order to efficiently obtain the } \\
\text { resources they discovered } \\
\text { (Searching as Exploration) }\end{array}$ & $\begin{array}{l}\text { - Use recommended databases to discover resources } \\
\text { - Search within relevant journals } \\
\text { - Use Find it at CU }\end{array}$ & $\begin{array}{l}\text { - } \quad \text { Sort and order } \\
\text { - } \quad \text { Export to Excel }\end{array}$ \\
\hline $\begin{array}{l}\text { Students will understand that research } \\
\text { is an iterative process in order to fully } \\
\text { engage with challenging questions } \\
\text { (Research as Inquiry) }\end{array}$ & $\begin{array}{l}\text { - Add resources to Zotero subcollection over time } \\
\text { - Use sources that span time periods }\end{array}$ & - $\quad$ Timeline \\
\hline
\end{tabular}

Table Two. Mapping outcomes and frames to observable actions and Zotero tools for case study. 